\title{
Correction to: Genetic and evolutionary analysis of enterovirus 71 base dinucleotide
}

\author{
Meng Wang ${ }^{1} \cdot$ Li Chen ${ }^{1} \cdot$ Wangjie Jin $^{2} \cdot$ Shasha Wang ${ }^{1}$
}

Published online: 22 February 2020

(C) Indian Virological Society 2020

\section{Correction to: VirusDis.}

https://doi.org/10.1007/s13337-019-00564-z

The article Genetic and evolutionary analysis of enterovirus 71 base dinucleotide, written by Meng Wang, Li Chen, Wangjie Jin, Shasha Wang, was originally published

electronically on the publisher's internet portal (currently SpringerLink) on 29 January 2020 with open access. With the author(s)' decision to step back from Open Choice, the copyright of the article changed on 22 February 2020 to (c) Indian Virological Society 2020 and the article is forthwith distributed under the terms of copyright.

The original article can be found online at https://

doi.org/10.1007/s13337-019-00564-z.

\section{Shasha Wang}

64878893@163.com

1 Nanfang PET Center, Nanfang Hospital, Southern Medical University, Guangzhou 510515, China

2 Department of Gynaecology and Obstetrics, Nanfang Hospital, Southern Medical University, Guangzhou 510515, China 